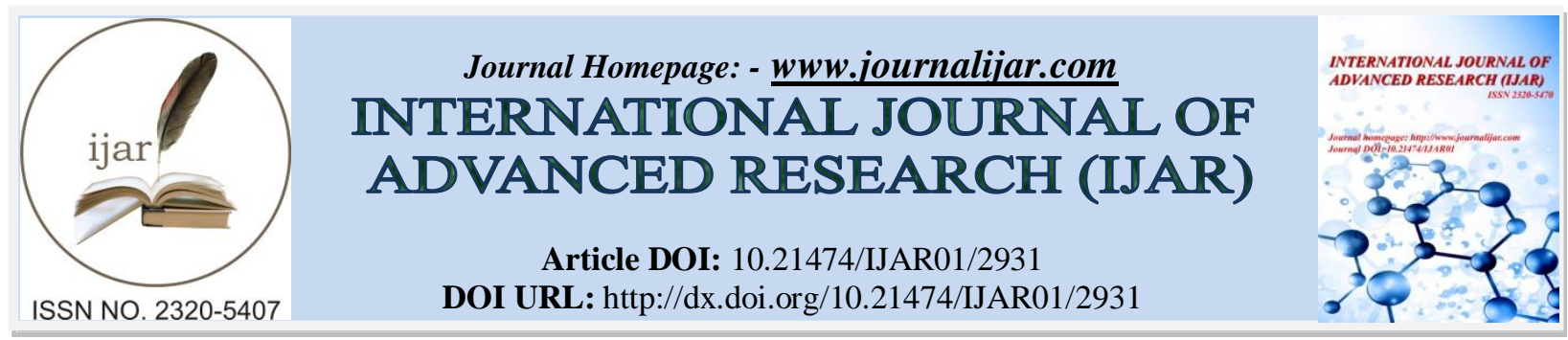

RESEARCH ARTICLE

\title{
PHILOSOPHICAL ASSUMPTION IN MEASURING AESTHETICS OF A BUILDING
}

Hyeladzira Garba Mshelia ${ }^{1}$, Rakiya Haruna Ibrahim ${ }^{2}$ and Alhaji Kasir Lawan ${ }^{2}$.

1. Department Of Architecture, Ramat Polytechnic Maiduguri, Borno State Nigeria.

2. Department Of Architecture, Ahmadu Bello University Zaria, Kaduna State.

\section{Manuscript Info}

Manuscript History

Received: 25 November 2016

Final Accepted: 27 December 2016

Published: January 2017

\section{Abstract}

The quality of being pleasing is aesthetics. The aesthetic of a building vary in responses to human observers, if it partly follows proportion, if there is symmetry of measurement. In this paper we try to explain domains that are not easily quantifiable and thus can be used to communicate information between individual perceptions.

Copy Right, IJAR, 2016,. All rights reserved.

\section{Introduction:-}

Definition of aesthetics:-

Is the quality of being pleasing, especially to look at, something that gives great pleasure, when looking at it.

The aesthetic of a building or designs vary in responses in human observers. It is not trivial, however, to relate these responses to particular characteristics of the art. The impacts on our emotional and mental world. In particular, it refers to the responses that indicate the degree of discrimination in perception when confronted with a design. This perception depends on the individual's interpretation, which may arise from emotional responses and/or comparison with previous experiences. The concern for most scholars contemplating aesthetic research is (at least) twofold:

1. How can aesthetic preference are empirically assessed.

2. How can aesthetic preference be compared pan-humans and cross-culturally. In most instances, what counts as empirical data for aesthetic preference relies on overtly expressed or articulated views at the level of verbal discourse (van Damme, 1996).

This paper addresses the issues concerned with variables or parameter use in measuring aesthetics of a building.

\section{Aesthetics:-}

Aesthetics has been described as dealing with "the philosophy of the beautiful as well as with the standards of value in judging art and other aspects of human life and culture" (Lawal, 1974). The term aesthetics was first used by Baumgasrten, a German philosopher, in the mid-1700s. Fay Sudweeks and Simeon J. Simoff. The perception of aesthetics is verbally described by closely interrelated terms like style, taste, originality and beauty.

Taking the example of an aesthetic design again, a style refers to designs that have identifiable common characteristics. For example, 'state style' in Adamawa state (Yola) Nigeria West Africa, building design usually refers to characteristics such as red brick walls with cement mortar, asbestos roof, and veranda columns. Personal preferences in style are connected with individual taste. Style and taste are connected with the originality and individuality of a design, although not everything original is aesthetic. Beauty is an even more abstract term and is 
often used to characterise aesthetics. Beauty is sometimes understood as a part of aesthetics, sometimes as a synonym of aesthetics, which introduces additional confusion.

1. Visual aesthetic appeal, according to Berlyne (1971), depends partly on the level of arousal triggered by a stimulus. Arousal is characterised in terms of the related variables of novelty, complexity and fronted with appropriate proportions of these collative variables.

2. Usurprisingness is measured by the degree of exploratory behavioural response in humans when conniversal aesthetics. The possible existence of universal aesthetics has piqued the interest of scholars from many disciplines, including philosophers, psychologists, anthropologists, cultural scientists and sociologists. According to Forge (1973), the existence of a universal human aesthetic is a matter of faith with neither those supporting nor those opposing the notion of a basic or genetic response to certain forms or proportions being able to prove their beliefs.

\section{The Vitruvian design principles:-}

Vitruvius (1st century BC) is probably the first person to lay forth systematic and elaborated principles of design. It is not surprising that architecture was the subject of his elaborated writings, being the most salient and complex design discipline, which has affected human. It is not difficult to see that there is much in common for architecture (Brooks, 1975; Hooper, 1986; Lee, 1991; Kim et al., 2002; Visser, 2009).

Considering Vitruvius's three core principles of sound architectural work.

Firmitas, which is the strength and durability of the building:-

utilitas -the utility of the building, its usefulness and its suitability for the needs of its intended inhabitants and users;

venustas - the building's beauty. In architecture, the Vitruvian principles have been influential since their rediscovery in the 15th century (Johnson, 1994; Kruft, 1994). To evaluate the design quality of a building (Whyte et al, 2003).

The appearance of a building:-

Attributes of the choice process were found to moderate the relation between aesthetic evaluation and product choice, especially when users are required to trade-off aesthetic for other system qualities. For example, Ben-Bassat et al (2006) found that system preference or choice were affected by aesthetics under ordinary conditions (e.g., questionnaires) but not when the participants had to bid for a system with which they will perform competitive tasks. Diefenbach and Hassenzahl (2007) showed that under a beauty-usability trade-off, although people may prefer more beautiful products to more usable ones, they choose the more usable product if they cannot justify choosing the more beautiful one.

\section{In Accordance With Good Taste:-}

1. Contextual factors, such as domain and type of task are mentioned by Norman (2004) as important considerations for the type of aesthetic design required for users' performance and satisfaction. He argues that in certain domains (e.g., control rooms) attractive design may not necessarily be desired. Ben-Bassat et al (2006) found that people weighed more usability over aesthetic factors when faced with a performance-oriented task, and Van Schaik and Ling (2008) demonstrated that attractiveness ratings were affected by providing context for the evaluation task.

2. Individual factors may also affect how antecedent variables (e.g., objective design attributes) are perceived differently by people with different aesthetic tastes (Hoyer and Stokburger-Sauer, 2011). In the domain of website design, Park et al., (2004) found that variability in user tastes is associated with aesthetic fidelity (i.e., the degree to which users felt the target impressions intended by designers). Individual differences were also found to affect the relative importance of aesthetics in people's preference of web-sites (Hartmann et al., 2008).

\section{Variables:-}

1. Cross cultural studies have shown that national and professional cultures affect various relationships between aesthetic evaluations, their antecedents and their consequences. Hartmann et al (2007) found that the aesthetic evaluations and the importance of aesthetics are contingent on users.

2. The contingent nature of the aesthetic process is exemplified by Moshagen et al's finding that high visual aesthetics improved performance under poor usability but had no effect under high usability. Consequently, they 
quoted Liu's (Liu 2003) principle that ergo-aesthetic design does not imply that workplace or product designers should only use designs that are pleasing or attractive. On the contrary, ergo-aesthetic design advocates the careful and proper selection of aesthetic levels of design to fit the needs and characteristics of the intended use.

\section{Conclusion:-}

These paper is on the assumption that beauty is on eye of the beholder, as various philosopher tries to conclude that aesthetic depend on individual perception, the appearance is pleasing and in accordance with good taste.

\section{References:-}

1. Alland, A. (1989). Affect and aesthetics in human evolution. Journal of Aesthetics and Art Criticism, 97(1), 114.

2. Hassenzahl, M. (2003). The Thing and I: Understanding the Relationship between User and Product in Blythe, M., Overbeeke, C., Monk, A.F., and Wright, P.C. (eds.) "Funology: From Usability to Enjoyment" Kluwer, pp.31-42

3. Jordan, P.W. (1999). Pleasure with Products: Human Factors for Body, Mind and Soul" in Green, W.S. and Jordan, P.W. (eds.) "Human Factors in Product Design" Taylor \& Francis

4. Kurosu, M. (2012). Three Dimensions of Artifact Design - Meaningfulness, QualityTraits and Kansei (in Japanese). Human Interface Symposium 2012

5. Moshagen, M. \& Thielsch, M. T. (2013). A short version of the visual aesthetics of websites inventory. Behaviour \& Information Technology, 32(12), 1305-1311.

6. Simeon, J. S. \& Fay, S. (n/d). Quantifying Beauty: An Information System for Evaluating Universal Aesthetics. Retrieved 3th January 2016 from http://www2.iath.virginia.edu/time/readings/ontology-semanticsmetaphor/metaphor-in-human-computer-interface.pdf

7. Tamar, B. B., Joachim, M. \& Noam, T. (2006). Economic and Subjective Measures Of The Perceived Value of Aesthetics and Usability. Article in journal of ACM Transactions on Computer-Human Interaction, Vol. 13, No. 2.

8. Wayne, D. H, \& Nicola, E. S. S. (2011). The role of aesthetic taste in consumer behavior Article in Journal of the Academy of Marketing Science 40(1):167. -180. 